Western University

Scholarship@Western

Psychiatry Publications

Psychiatry Department

9-6-2018

\title{
A Review of the Pharmacological and Clinical Profile of Newer Atypical Antipsychotics as Treatments for Bipolar Disorder: Considerations for Use in Older Patients.
}

\author{
Akshya Vasudev \\ Western University, akshya.vasudev@uwo.ca \\ Sumit Chaudhari \\ Western University \\ Rickinder Sethi \\ Rachel Fu \\ Rachel M Sandieson \\ Western University \\ See next page for additional authors \\ Follow this and additional works at: https://ir.lib.uwo.ca/psychiatrypub \\ Part of the Psychiatry and Psychology Commons
}

Citation of this paper:

Vasudev, A., Chaudhari, S., Sethi, R. et al.(2018) A Review of the Pharmacological and Clinical Profile of Newer Atypical

Antipsychotics as Treatments for Bipolar Disorder: Considerations for Use in Older Patients. Drugs Aging. https://doi.org/10.1007/

s40266-018-0579-6 
Authors

Akshya Vasudev, Sumit Chaudhari, Rickinder Sethi, Rachel Fu, Rachel M Sandieson, and Brent P Forester 


\title{
A Review of the Pharmacological and Clinical Profile of Newer Atypical Antipsychotics as Treatments for Bipolar Disorder: Considerations for Use in Older Patients
}

\author{
Akshya Vasudev $^{1,5}$ [D Sumit Chaudhari ${ }^{1} \cdot$ Rickinder Sethi $^{1} \cdot$ Rachel Fu $^{6} \cdot$ Rachel M. Sandieson $^{2} \cdot$ Brent P. Forester $^{3,4}$
}

(c) Springer Nature Switzerland AG 2018

\begin{abstract}
Bipolar disorder prevalence rates vary in the older adult population (defined as age $\geq 65$ years), ranging from $1 \%$ in community dwellers to as high as $8-10 \%$ in hospital inpatients. Although older agents, including lithium and valproic acid, offer significant antimanic efficacy, as supported by a recent randomized controlled trial (RCT), there is growing interest in using atypical antipsychotics to treat bipolar disorder in older adults. Newer atypical antipsychotics are of interest based on their tolerability and efficacy in the general adult bipolar population. The aim of this review was to systematically examine efficacy and tolerability of newer atypical antipsychotics for older adult bipolar disorder (OABD). We conducted a systematic search utilizing the MEDLINE, EMBASE, PsycINFO and Cochrane Library electronic databases, with the aim of identifying all RCTs comparing newer atypical antipsychotics approved by the US FDA since 2002 (including brexpiprazole, cariprazine, lurasidone, iloperidone, asenapine, paliperidone, and aripiprazole) with placebo or another comparator, in the treatment of any phase of bipolar disorder (including mania, depression or mixed episodes while used as an acute or maintenance treatment) in older adults ( $>65$ years). We found no RCT data on any of the examined agents. Hence, we changed our search criteria to include studies with a lower age cut-off ( $\geq 55$ years), as well as the inclusion of post hoc studies. Two post hoc studies on lurasidone suggest its reasonable safety and efficacy profile in the acute and maintenance treatment of OABD; however, there are no pharmacoeconomic data on the use of lurasidone in the treatment of OABD. Research data from open-label studies on oral asenapine and aripiprazole as add-on therapy suggest that these two agents are adequately tolerated and improved symptoms of depression and mania in OABD; hence, there is an urgent need to conduct RCTs on these two agents. Lastly, we found no studies for the treatment of OABD with brexpiprazole, cariprazine, iloperidone, or paliperidone.
\end{abstract}

Akshya Vasudev

akshya.vasudev@uwo.ca

1 Division of Geriatric Psychiatry, Department of Psychiatry, Western University, London, ON, Canada

2 Western Libraries, Western University, London, ON, Canada

3 Division of Geriatric Psychiatry, McLean Hospital, Belmont, MA, USA

4 Department of Psychiatry, Harvard Medical School, Boston, MA, USA

5 Department of Medicine, Western University, London, ON, Canada

6 Department of Pharmacy, London Health Sciences Centre, A2-607, Victoria Hospital, 800 Commissioners Road East, London, ON N6A 5W9, Canada

\section{Key Points}

Lithium and valproic acid remain the gold-standard agents for the treatment of bipolar disorder, but they are often not well tolerated in the older adult bipolar disorder (OABD) population. Newer atypical antipsychotics are of interest, based on some efficacy in the general adult population.

No randomized controlled data are available on brexpiprazole, cariprazine, lurasidone, iloperidone, asenapine, or aripiprazole in the treatment of OABD.

Post hoc data suggest lurasidone to be effective and well tolerated in OABD.

Randomized controlled studies of newer atypical antipsychotics in $\mathrm{OABD}$ are urgently required. 


\section{Introduction}

Evidence suggests the prevalence rates of older adult bipolar disorder (OABD) range from $1 \%$ in communitydwelling seniors to as many as $8-10 \%$ of geriatric inpatient admissions and $17 \%$ of geriatric psychiatry emergency visits [1]. With a successfully aging society across the world, it is predicted that the population of those above 60 years of age will grow 3.5 times more rapidly than the rest of the population [2]. With overall improvement in health care, patients suffering from bipolar disorder are expected to live longer into their late life. This will inevitably lead to greater socioeconomic burden on the healthcare system, in addition to a greater proportion of individuals with OABD presenting to the primary care physician's office and the emergency room, as well as accessing psychiatric services.

Optimal management of bipolar disorder requires both acute and maintenance treatment. Current guidelines endorse the use of lithium as the prototypical mood stabilizer, and/or the antiepileptic valproic acid, along with antipsychotics, as augmenting agents to stabilize mood and/or manage agitation in the acute phase, as well as continuation of some of these agents in the maintenance phase $[3,4]$. Guidelines also recommend using antidepressants in combination with a mood stabilizer for acutely treating depressive symptoms. While one of these guidelines does offer some insight into the management of OABD [4], it does not offer a detailed review of the safety and efficacy of newer atypical antipsychotics for the treatment of OABD.

Current literature guided the first international task force on the treatment of late-life bipolar disorder [2] to recognize an upcoming epidemic of the older-aged bipolar cohort. It also acknowledged the need for a specific treatment approach for this population compared with the adult patient with bipolar disorder. The effects of aging per se lead to comorbidity with other physical illnesses such as cardiovascular disease [5, 6], cerebrovascular disease [7], diabetes mellitus, cancer [8], neurological conditions [9], and premature mortality from general medical conditions [10]. These illnesses require treatment with additional medications, which increases the risk of drug interactions and adverse effects [11]. Additionally, there are pharmacokinetic changes in drug metabolism due to age-related reduction in renal clearance, increased risk of drug sensitivity to drugs acting on the central nervous system [12, 13], and cognitive decline associated with aging [14]. Other consensus guidelines recognize these biological factors and recommend using lower doses of all psychotropics in the older-age bipolar patient [3].

The clinical management of OABD continues to be largely based on expert consensus and extrapolated from studies of the general adult bipolar population [15-18]. The first large randomized controlled trial (RCT) on the management of acute mania in late-life bipolar disorder patients, the GERI-BD study, has recently been published [19]. Findings indicated a significant improvement in mania scores with lithium compared with valproate in the early stages of acute treatment [19]; however, there was no significant difference in response rates between the two arms [19].

Over the last 15 years, newer atypical antipsychotics, such as lurasidone, aripiprazole, asenapine, and cariprazine, have been approved by the US FDA for the treatment of schizophrenia. Additionally, some of these agents have been approved for the treatment of the acute and/or maintenance phase of bipolar illness in the general adult population, while some have also been approved for use in the child and adolescent bipolar population; however, none of these agents are currently approved for the treatment of OABD. Theoretically, these agents might offer similar efficacy rates compared with the general adult population; however, there are no published reviews evaluating the safety or efficacy of these agents in the OABD population. Safety concerns of these agents include extrapyramidal side effects related to dopamine receptor $\left(\mathrm{D}_{2}\right)$ blockade (e.g. aripiprazole and brexipiprazole) and potential metabolic side effects. Therefore, we aimed to review the safety and efficacy of these newer atypical antipsychotics in the management of the OABD. Such a review will hopefully better inform the treating clinician, as well as inform the therapeutic potential of these agents in this growing and difficult-to-manage population.

We searched all related bipolar disorder terms in the Ovid MEDLINE (In-Process and Other Non-Indexed Citations, Ovid MEDLINE Daily and Ovid MEDLINE), EMBASE (EMBASE Classic and EMBASE), PsycINFO, and the Cochrane Library/EBM Reviews electronic databases. Search duration was from database inception to 7 April 2017. We specifically included the following atypical antipsychotics that have been approved by the FDA since 2002: brexpiprazole, cariprazine, lurasidone, iloperidone, asenapine, paliperidone, and aripiprazole. Filters for patients aged $\geq 65$ years, and RCTs, were added. To identify any currently ongoing or yet-to-be-published studies, we searched the ClinicalTrials.gov registry database, as well as relevant psychiatry conferences, for related abstracts over the last 5 years. Our outcome criteria included change in mood scores and proportion of participants achieving a priori criteria of remission or response (e.g. $50 \%$ fall in a mania or depression rating scale), while secondary outcomes were rate of inpatient admission and readmission, change in function, quality of life, metabolic side effects, and response on comorbid psychiatric symptoms such as anxiety.

Using these approaches, we were not able to identify any RCTs conducted of these agents in OABD. When 
subsequently expanding our search to post hoc studies assessing data from previous RCTs with a reduced age threshold of $\geq 55$ years, we identified two post hoc studies of lurasidone in the treatment of late-life bipolar disorder. Details of the findings of these studies, as well as a description of the pharmacological profile, safety, and efficacy data from non-RCT design studies conducted on the other atypical antipsychotics, are provided below. In addition, we offer recommendations on the use of each agent in OABD based on such data.

\section{Newer Atypical Antipsychotics for Older Adult Bipolar Disorder}

The mood stabilizers lithium and valproic acid have been the mainstay of bipolar management across all age groups for at least the last 30 years [20]. It is well known that while lithium has an excellent antimanic, antidepressant and antisuicidal effect, it suffers from a very narrow therapeutic index [20]. Valproic acid also offers good antimanic effect, but its use needs to be regularly monitored for risk of bone marrow suppression, hepatotoxicity, hyperammonemia and encephalopathy [21-23]. With advancing age, older adults experience physiological changes that affect drug pharmacokinetics, including changes in drug distribution, metabolism, and excretion [24]. The impact of reduction in total body water composition, reduced glomerular filtration rate, and reduced hepatic function in older adults further narrows the therapeutic index for lithium and valproic acid derivatives [25, 24]. In addition, older adults tend to be more sensitive to the pharmacodynamic effects of all drugs [24, 26]. They also tend to have more comorbidities, leading to increased risk of drug-drug interactions and drug-disease interactions [11].

Research shows that over the last few years there has been an explosion of data on the use of newer atypical antipsychotics in the treatment of bipolar disorder across the age span. Besides their efficacy potential, such agents demonstrate a relatively wider therapeutic index compared with lithium or valproate.

\subsection{Brexpiprazole}

Brexpiprazole is the most recently approved agent, approved by the FDA in 2015 for the treatment of schizophrenia and as an adjunctive therapy for the treatment of major depressive disorder. Like other atypical antipsychotics, brexpiprazole is a serotonin-dopamine neurotransmitter modulator [27]. It differs from other agents by being a partial agonist at 5- $\mathrm{HT}_{1 \mathrm{~A}}$ and dopamine $\mathrm{D}_{2}$ receptors, and is an antagonist a serotonin 5- $\mathrm{HT}_{2 \mathrm{~A}}$ and adrenergic ${ }_{\alpha 1 \mathrm{~B} / 2 \mathrm{C}}$ receptors [27]. In vitro, brexpiprazole exhibits more $\mathrm{D}_{2}$ blockade than aripiprazole. It is well absorbed, is metabolized by cytochrome P450 (CYP)
2D6 and CYP3A4, and has a long half-life of $91 \mathrm{~h} \mathrm{[28].}$ Dosing considerations in the elderly include manufacturerrecommended dose adjustments for concurrent CYP2D6 or 3A4 inhibition [28]. In addition, a recommended reduction of maximum daily dose from 4 to $3 \mathrm{mg} /$ day is suggested in the setting of moderate to severe hepatic dysfunction or moderate to severe end-stage renal disease [28]. There were no clinically relevant effects on the ECG QT interval, as well as minimal changes on serum prolactin levels [28].

There is currently an ongoing trial (NCT03259555) assessing the safety and tolerability of brexpiprazole in adults with bipolar mania with or without mixed episodes. Although the tolerance and safety of this agent has not been assessed in adults with bipolar disorder, some of the safety aspects have been studied in schizophrenia. Akathisia (5.8\%) and weight gain (4.7\%) were reported in a study of 1256 patients taking brexpiprazole $6 \mathrm{mg} /$ day compared with placebo [29]. A newly diagnosed metabolic syndrome was also more common compared with placebo $(1.2 \%$ vs. $0.8 \%)$ in the short-term, and even higher (3.1\%) in longer-term trials [29]. Brexpiprazole did not increase the QT interval in the trials [29].

We suspect that due to the recent marketing approval of brexpiprazole (2015), no data are as yet available regarding either the safety or efficacy of this agent in adult or late-life bipolar disorder.

While the pharmacological profile of this agent is somewhat unique, including activity on multiple receptor targets associated with bipolar disorder and a long half-life, which could offer benefits for patients unable to maintain drug adherence, the lack of any data on OABD prevents us from offering any recommendations of its use in this indication.

\subsection{Cariprazine}

Cariprazine was also approved in 2015 for the treatment of schizophrenia and acute bipolar disorder. Its pharmacological profile includes being a $\mathrm{D}_{2}$ partial agonist, similar to aripiprazole [30]. It also exhibits a dose-dependent preference for occupying $D_{3}$ receptors at low doses, with increasing occupation of $\mathrm{D}_{2}$ receptors as the dose increases [30]. In addition, it displays $5-\mathrm{HT}_{1 \mathrm{~A}}$ agonism effects $[31,30]$. Cariprazine is metabolized by CYP3A4, and the manufacturer recommends a 50\% dose reduction when coadministered with a strong CYP3A4 inhibitor such as ketoconazole $[31,30]$. Furthermore, cariprazine also has a long half-life of 48-96 h, while its active metabolite, didesmethyl cariprazine, exhibits a half-life of $1-3$ weeks $[31,30]$. This could manifest as a theoretical lack of an acute response and/ or management of agitation in the first few weeks of dose titration $[31,30]$. It is also recommended that cariprazine be started at a lower dose and titrated much slower in the elderly due to the risk of orthostatic hypotension $[31,30]$. 
Cariprazine has been evaluated in adults with bipolar manic or mixed episodes. In a phase II trial, patients aged 18-65 years treated with cariprazine $3-12 \mathrm{mg} / \mathrm{day}$ demonstrated significant improvement in manic symptoms using the Young Mania Rating Scale (YMRS), in addition to improvements on the Clinical Global Impression (CGI) scale [32]. However, patients taking cariprazine experienced more instances of akathisia (22\%, vs. $6 \%$ with placebo) and parkinsonism (16\% vs. 1\%) [32]. In another phase III trial of patients aged 18-65 years, the efficacy of low-dose (3-6 mg/day) cariprazine was similar to that of high-dose cariprazine (6-12 mg/day) [33]. The most common adverse effects from these studies include akathisia, parkinsonism, and other extrapyramidal symptoms (EPS; $9.6 \%$ and $11.2 \%$ at doses of 3-6 mg and 6-12 $\mathrm{mg}$, respectively), which was almost twice the placebo rates (5.6\%) [33]. Other common adverse effects were constipation $(4.8 \%$ and $10.7 \%$ at doses of 3-6 mg and 6-12 mg, respectively) compared with placebo $(2.5 \%)$ [32]. Commonly reported adverse effects with other atypical antipsychotics, such as weight gain, metabolic disturbances, changes on ECG, or elevated prolactin have, to date, not been reported with cariprazine [34, 35].

We found both an ongoing trial and a recently completed trial assessing the efficacy and tolerability of this agent in bipolar depression (NCT02670538, NCT01396447). However, at the time of this publication, no study results were available on the safety and efficacy of cariprazine in OABD. and hence there is insufficient data to recommend its use.

\subsection{Lurasidone}

Lurasidone was approved by the FDA in 2013 for the monotherapy treatment of bipolar depression [36]. It exhibits high affinity as well as strong antagonism at $\mathrm{D}_{2}, 5-\mathrm{HT}_{2 \mathrm{a}}$, and $5-\mathrm{HT}_{7}$ receptors [37]. It also acts as a partial agonist at the $5-\mathrm{HT}_{1 \mathrm{a}}$ receptors. These effects could be of benefit in controlling comorbid anxiety [37]. Additionally, it is a muscarinic and histaminergic receptor-sparing agent [37], which could theoretically offer better tolerability in the older aged population due to concerns of cognitive impairment with drugs that block such receptors. Lurasidone is primarily metabolized by CYP3A4, and hence it should be cautiously coadministered with inducers or inhibitors of CYP3A4 [38]. The half-life of lurasidone is $18 \mathrm{~h}$, which provides simplicity in once-daily dosing [37, 38]. The drug information approved by the FDA suggests starting lurasidone at a $40 \mathrm{mg}$ once-daily dose and with slow titration until therapeutic response or lack of tolerability, with a maximum recommended daily dose of $160 \mathrm{mg}$ [39]. This medication should always be consumed with a meal containing at least 350 calories [39].

A post hoc analysis of an older adult cohort was conducted on data from two previous double-blind, placebo-controlled studies of lurasidone in the acute treatment of adult bipolar depression [40]. This post hoc analysis specifically evaluated the efficacy and safety of lurasidone in a late-life bipolar depression sample ( $n=142$, age $>55$ years). Lurasidone was administered at $20-120 \mathrm{mg} /$ day, either as monotherapy or adjunctive therapy to either lithium or valproate [40]. In the monotherapy group, a mean change at week 6 on the Montgomery-Asberg Depression Rating Scale (MADRS) was significantly greater for lurasidone versus placebo $(-14.8$ vs. $-7.1 ; p=0.003$; effect size 0.83 ; pooled doses), while in the adjunctive therapy group, mean change in MADRS scores in the lurasidone group was not significantly different from the placebo group ( -13.9 vs. $-11.1 ; p=0.398$; effect size 0.26) [40]. Lurasidone was found to be safe and well-tolerated, as evidenced by reasonably low discontinuation rates in both the monotherapy and adjunctive therapy studies $(<7.1 \%)$ [40]. Additionally, there were minimal effects on metabolic laboratory values [40].

The same research group [41] also conducted a post hoc analysis of a 6-month open-label extension maintenance study of lurasidone in 141 older adults as either monotherapy or augmentation therapy. Patients were aged 55-75 years and had previously completed 6 weeks of a double-blind, placebo-controlled treatment with either lurasidone 20-120 mg/day monotherapy, or augmentation with lithium or valproate [41]. There was minimum increase in weight $(-1.0 \mathrm{~kg}$ and $-0.4 \mathrm{~kg}$, monotherapy or augmentation, respectively); total cholesterol $(-2.0 \mathrm{mg} / \mathrm{dL}$ and $+6.0 \mathrm{md} / \mathrm{dL}$, respectively), triglycerides $(+2.5 \mathrm{mg} / \mathrm{dL}$ and $+6.0 \mathrm{mg} / \mathrm{dL}$, respectively), and $\mathrm{HbA} 1 \mathrm{c}(0.0 \%$ and $-0.1 \%$, respectively) [41]. Adverse events occurring at any time in the 6-month open-label phase were as follows for the monotherapy and adjunctive therapy groups: headache $(14.5 \%$, $10.5 \%)$, nasopharyngitis $(10.9 \%, 4.7 \%)$, fatigue $(9.1 \%$, $3.5 \%)$, insomnia $(7.3 \%, 11.6 \%)$, anxiety $(7.3 \%, 7.0 \%)$, and depression $(7.3 \%, 4.7 \%)$. The rates of extrapyramidal side effects were reported for akathisia $(3.6 \%, 11.6 \%)$, tremor $(1.8 \%, 8.1 \%)$, and parkinsonism $(3.6 \%, 7.0 \%)$ [41]. No clinically meaningful treatment-emergent changes were observed in vital signs, ECG parameters, or blood chemistries during this time [41]. One male and one female in the monotherapy group (and none in the adjunctive therapy group) had a clinically significant increase in prolactin levels [41]. There was a significant fall in MADRS scores in both the monotherapy $(-6.2)$ and adjunctive therapy $(-6.7)$ groups [41].

The above data suggest that lurasidone offers significant potential to control depressive symptoms in both the acute and maintenance phases of OABD. The lack of serious adverse events and overall metabolic safety suggests its potential role for clinical use in OABD. Data on the pharmacoeconomic benefits, as well as the long-term effects on cardiovascular and cerebrovascular parameters, are still needed. 


\subsection{Iloperidone}

Iloperidone was approved by the FDA in 2009 for the treatment of schizophrenia. It has an oral bioavailability of $96 \%$ and does not require any caloric supplementation, unlike lurasidone [42]. The effective dose range has been estimated to be between 12 and $24 \mathrm{mg} /$ day [42, 43]. It is suggested that the dose be slowly titrated from $1 \mathrm{mg}$ twice daily, by doubling the dosage daily to avoid orthostatic hypotension [42, 43]. Iloperidone demonstrates high binding affinity for $D_{2}$ and $D_{3}$ receptors, $\alpha 1$-adrenergic receptors, and 5- $\mathrm{HT}_{2} \mathrm{~A}$ [42]; however, receptor affinity for $\mathrm{D}_{2}$ and $5-\mathrm{HT}_{2} \mathrm{~A}$, is low compared with other antipsychotics such as lurasidone and asenapine [44]. Iloperidone demonstrates moderate affinity for $\alpha 2$ receptors, and therefore may have greater risk of orthostatic hypotension [45, 46]. It also shows mild antagonism on 5- $\mathrm{HT}_{1 \mathrm{~A}}$ receptors [44]. Finally, it exhibits minimal affinity for $\mathrm{H} 1$ receptors, thus theoretically offering limited sedation and weight gain [46]. Iloperidone is extensively metabolized by CYP3A4 and CYP2D6 [42]. It is therefore recommended that the dose be reduced by $50 \%$ when coadministered with potent inhibitors of these cytochrome systems. There are no adjustment recommendations in patients with hepatic or renal impairment, however, Sedek et al., noted a doubling of half-life in patients with renal impairment compared with healthy controls (33.7 vs. $15 \mathrm{~h} ; p<0.05)[44,47]$.

A pooled analysis of three RCTs in schizophrenia noted most common adverse events of iloperidone were dizziness, headache, dry mouth, nausea, and insomnia [48, 49]. The rates of discontinuation due to adverse events were not statistically different between iloperidone and placebo (4.8\% for both) and were lower than risperidone (6.2\%) and haloperidol $(7.6 \%)$ [48, 49]. Iloperidone-treated patients showed significantly low rates of akathisia compared with haloperidol and risperidone [49]. However, iloperidone-treated patients demonstrated a significant increase in weight of up to $2.1 \mathrm{~kg}$ during the 6-week intervention, which was greater than risperidone $(+1.5 \mathrm{~kg})$ and placebo $(-0.3 \mathrm{~kg})$ [49]. In addition, iloperidone-treated patients had at least a mild increase in serum glucose [49]. There was a linear dose response with the mean increase in serum glucose of $7.2 \mathrm{mg} / \mathrm{dL}$ [standard deviation (SD) $1.8-12.6]$ in the iloperidone $4-8 \mathrm{mg} / \mathrm{day}$ group versus $16.2 \mathrm{mg} / \mathrm{dL}$ (SD 3.6-27) in the 20-24 mg/day group [49]. The authors also observed a significant linear increase in the QTcF interval on their ECG in the iloperidone-treated arm (2.9 $\mathrm{ms}$ in the $4-8 \mathrm{mg} /$ day dose group vs. $9.1 \mathrm{~ms}$ in the 20-24 mg/day dose group) [49].

This review did not identify any ongoing or published studies of iloperidone for the acute or maintenance phases of treatment of either adult or late-life bipolar disorder, and hence no clinical recommendations can be offered.

\subsection{Asenapine}

Asenapine is a newer-generation antipsychotic approved by the FDA in 2009 for the treatment of schizophrenia, as well as for the management of acute mania or mixed episodes associated with bipolar I disorder. Its mechanism of action includes being a potent antagonist at dopamine $\mathrm{D}_{2}$ and serotonin $5-\mathrm{HT}_{2 \mathrm{~A}}$ receptors [50]. It also binds to serotonin $5-\mathrm{HT}_{1 \mathrm{~A}}, 5-\mathrm{HT}_{2 \mathrm{C}}, 5-\mathrm{HT}_{6}, 5-\mathrm{HT}_{7}$, histamine $\mathrm{H}_{1}$ and noradrenergic $\alpha 1$ receptors [50]; however, it has negligible affinity for muscarinic $\mathrm{M}_{1}$ receptors [50]. It also acts as a partial agonist at 5- $\mathrm{HT}_{1 \mathrm{~A}}$ receptors [50], which could contribute to its additional antianxiety effects. One study showed a low incidence of orthostatic hypotension and dizziness despite the potent antagonist effects of asenapine at noradrenergic $\alpha 1$ receptors [50]. Asenapine is the only antipsychotic drug that is available exclusively in sublingual form. Its bioavailability is approximately $35 \%$, which reduces further if taken with food or water [51]. Although the terminal half-life is approximately $24 \mathrm{~h}$, it is usually administered twice daily because the limited surface area in the oral cavity may limit the extent of drug absorption for high doses [51]. Asenapine is primarily metabolized via glucuronidation by UGT1A4, and undergoes oxidative metabolism by CYP1A2 [52]; however, smoking, which is known to induce CYP1A2, does not appear to impact the metabolism of asenapine [52]. As it is taken in a sublingual form, it is known to be rapidly absorbed, and leads to at least mild to moderate somnolence. Such an effect is likely efficacious in the treatment of agitation [52], a presenting feature of acute mania. The manufacturer does not recommend dosage adjustments for older adults, but a clinical trial in patients with schizophrenia found that the clearance of asenapine was inversely proportional to age. It was also found that elderly adults (aged 65-85 years) were exposed to $30 \%$ more drug than younger adult patients [53]. However, despite the increased exposure, short-term asenapine treatment was generally well tolerated in elderly patients with psychosis during rapid dosage escalation [54].

We identified a 12-week, prospective, open-label study designed to assess the efficacy and tolerability of adjunctive asenapine ( $n=15$, initiated at $5 \mathrm{mg} /$ day and titrated as tolerated) in a non-dementia older adult sample ( $\geq 60$ years of age) with suboptimal previous response to other bipolar disorder treatments [53]. There was global improvement in psychotic, manic, and depressive symptoms $(p<0.05)$ [53]. The most commonly reported adverse effects were gastrointestinal discomfort $(n=5,33 \%)$, restlessness $(n=2,13 \%)$, tremors $(n=2,13 \%)$, cognitive difficulties $(n=2,13 \%)$, and sluggishness $(n=2,13 \%)$ [53]. It is worth mentioning that asenapine is known to cause oral hypoesthesia [number needed to harm (NNH) 20, 95\% confidence interval (CI) 13-50] [54]. Additionally, cognitively impaired older bipolar 
patients may not be able to follow the specific instructions for its sublingual administration only.

While asenapine has a favorable pharmacological profile, which could theoretically be of benefit in treating OABD, the lack of any large-scale RCT data, and the reasonably poor acceptability rate, limits the support for the clinical utility of asenapine in OABD.

\subsection{Paliperidone}

Paliperidone was approved by the FDA in 2006 for the treatment of schizophrenia, and in 2009 for schizoaffective disorder. Its approved dose range for administration is $3-12 \mathrm{mg} /$ day [55]. It is the 9-hydroxy-risperidone metabolite of risperidone and therefore has a receptor affinity and adverse effects profile similar to risperidone [55]. Both risperidone and paliperidone have antagonistic activity at the $\alpha_{1}, \alpha_{2}, D_{2}$, $\mathrm{H}_{1}$, and 5- $\mathrm{HT}_{2 \mathrm{~A}}$ receptors [55]; however, paliperidone has been reported to have lower affinity for $\alpha_{2}, 5-\mathrm{HT}_{2 \mathrm{~A}}, 5-\mathrm{HT}_{1 \mathrm{~A}}$, and 5-HT ${ }_{1 \mathrm{D}}$ compared with risperidone [55]. Adverse effects reported as common to both agents include weight gain, insulin resistance, poor blood glucose control and hyperprolactinemia [56]. A recent review suggests that all these adverse effects are not clinically significant [56], while other studies suggest that paliperidone causes a greater increase in prolactin compared with its congener risperidone $[57,58]$. Oral paliperidone is available as an extended-release (ER) tablet that is administered once daily, which offers some pharmacokinetic advantage over the twice-daily administration of risperidone [56]. Per the manufacturer, the shell of the ER tablet does not deform as it moves through the gastrointestinal tract [59]. It is suspected that this can cause problems for patients with pre-existing inflammatory bowel disease or pre-existing gastrointestinal tract narrowing, although incidence rates for gastrointestinal obstruction are unknown [59]. Paliperidone is cleared renally, and the manufacturer recommends a dose of $3 \mathrm{mg}$ once daily in patients suffering mild renal impairment (creatinine clearance $\geq 50 \mathrm{~mL} / \mathrm{min}$ to $<80 \mathrm{~mL} / \mathrm{min}$ ) [59]. The dose may be increased to a maximum of $6 \mathrm{mg}$ once daily based on clinical response and tolerability [59]. For patients with moderate to severe renal impairment (creatinine clearance $\geq 10 \mathrm{~mL} / \mathrm{min}$ to $<50 \mathrm{~mL} / \mathrm{min}$ ), the recommended initial dose is $1.5 \mathrm{mg}$ once daily, which may be increased to a maximum of $3 \mathrm{mg}$ once daily [59]. Similar dose adjustments are suggested for the injectable form of paliperidone in patients with renal impairment [59].

We found no randomized controlled or open-label trials of paliperidone ER in late-life bipolar disorder; however, we did find two trials of paliperidone in adult bipolar disorder samples. Berwaerts et al., 2011 studied paliperidone in a randomized, placebo-controlled design as adjunctive therapy to lithium or valproate in the treatment of acute mania (age 18-65 years). Eligible patients $(n=300)$ had a mild to moderate manic syndrome, as evidenced by a YMRS total score $\geq 20$ [60]. Participants were randomly allocated (1:1) to continue their mood stabilizer monotherapy or receive flexibly administered paliperidone (3-12 $\mathrm{mg} /$ day) as augmentation treatment for 6 weeks [60]. There was a non-significant difference in change scores from baseline to endpoint in the YMRS total score for augmentation with paliperidone [-14.3 (SD 10.0)] compared with ongoing mood stabilizer monotherapy [-13.2 (SD 10.9); $p=0.16]$ [60]. The incidence of treatment-emergent adverse events was higher with augmentation treatment $(70 \%)$ than with mood stabilizer monotherapy (54\%) [60]. Insomnia was the most commonly reported adverse event in both treatment groups (11\%) [60].

In another randomized, placebo-controlled study, oral paliperidone ER was used as maintenance treatment in patients with bipolar I disorder after resolution of the acute manic phase [61]. Study participants included 766 patients aged 18-65 years administered flexible-dose paliperidone (3-12 mg/day) or olanzapine (5-20 mg/day) during a 3-week acute treatment phase before entry into the maintenance phase [61]. They found that the median time to recurrence of any mood symptoms in the maintenance phase was 558 days with paliperidone ER, and 283 days with placebo, while there was lack of recurrence of mood symptoms on patients taking olanzapine [61]. Overall, the time to recurrence of any mood symptoms was significantly longer with paliperidone ER than placebo $[p=0.017$; hazard ratio (placebo: paliperidone ER; unweighted 95\% CI): 1.43 (1.03; 1.98)] [61]. Such a difference was found to be significant for preventing recurrence of manic symptoms, but interestingly not for depressive symptoms [61].

The pharmacological profile of paliperidone ER offers some theoretical safety benefit over risperidone in the treatment of bipolar disorder; however, this is not supported by similar prevalence rates of adverse events with this agent. Additionally, its role in acute and maintenance treatment of adult bipolar treatment is weak, as per published RCT data. Lastly, there are no ongoing or completed trials of this agent in late-life bipolar disorder, and hence it cannot be recommended for routine use in the management of this disorder.

\subsection{Aripiprazole}

Aripiprazole was approved by the FDA in 2002 for the treatment of schizophrenia, in 2004 for acute manic and mixed episodes, and in 2007 as an adjunct for major depressive disorder [62]. Aripiprazole is marketed in doses ranging from 2 to $30 \mathrm{mg} /$ day, with a recommended starting oral dose of $15 \mathrm{mg} /$ day in schizophrenia and acute manic and mixed episodes of bipolar [63]. In addition, in July 2017, Abilify Maintena, an ER injectable suspension of aripiprazole, was 
approved by the FDA for maintenance monotherapy treatment of bipolar I disorder in adults [64].

The pharmacology of aripiprazole is somewhat unique in being the first atypical antipsychotic with $\mathrm{D}_{2}$ partial agonist activity [63]. It also has partial agonist activity at the $5 \mathrm{HT}_{1 \mathrm{~A}}$ receptors and antagonist activity at $5 \mathrm{HT}_{2 \mathrm{~A}}$ receptors [63]. Aripiprazole is well absorbed and administered once daily due to its long half-life of $146 \mathrm{~h}$ [63]. It is known to undergo hepatic metabolism via CYP2D6 and CYP3A4 to its active metabolite dehydroaripiprazole [63]. Patients taking a strong CYP3A4-inducing medication such as carbamazepine should double the oral dose of aripiprazole over 1-2 weeks [63]. Patients who are slow CYP2D6 metabolizers, or taking a CYP2D6 or CYP3A4 inhibitor, may require half the usual dose, while patients who are taking concomitant strong CYP2D6 and CYP3A4 inhibitors may require one-quarter of the usual dose of aripiprazole compared with patients not impacted by CYP2D6 or 3A4 activity [63].

In the elderly, it is recommended to start on a lower dose and titrate slowly. As a result of partial $\mathrm{D}_{2}$ agonism, and less $\mathrm{D}_{2}$ blockade, aripiprazole has been found to have a lower incidence of EPS compared with some antipsychotics [65]. Furthermore, it offers the least risk of hyperprolactinemia [65]. Additionally, it seems to have lesser sedative potential than other antipsychotics [65]. Lastly, a large comparative efficacy and tolerability meta-analysis of 15 antipsychotics used in the treatment of schizophrenia showed that aripiprazole caused at least a mild grade of weight gain compared with other antipsychotics, and caused significant weight gain compared with placebo (standardized mean difference $-0.17,95 \% \mathrm{CI}-0.28$ to -0.05 ; a negative value suggests more weight gain compared with placebo) [65].

The recent Canadian Network for Mood and Anxiety Treatments (CANMAT) treatment guidelines indicated that aripiprazole monotherapy can be used as first-line therapy for the treatment of acute mania, and in maintenance therapy of adult bipolar disorder [4]. These guidelines continue to recommend that this agent not be used as a monotherapy agent in acute depression [4]. Based on the available evidence, these guidelines also suggest a level 4 recommendation for the use of aripiprazole in the treatment of OABD based on a single open-label study. This particular study was a 12-week prospective trial of add-on oral aripiprazole in 20 adults aged 50 years and older in the acute treatment of bipolar disorder [66]. Patients were administered oral aripiprazole initiated at doses of $5 \mathrm{mg} / \mathrm{day}$, and the dose was increased as tolerated. Participants had a significant reduction in their mean depression scores on the Hamilton Depression Scale (HAM-D), from a baseline score of 13.8 (SD 6.6) to 6.1 (SD 3.71) $[p<0.001]$ in the 12-week period [66]. Additionally, there was an improvement in mania symptoms on the YMRS; baseline scores of 8.6 (SD 5.66) fell to 3.9 (SD 2.05) $[p<0.03]$ [66]. There were also significant improvements in functional status as measured by the Global Assessment Scale (GAS; $p<0.001$ ) [66]. The mean \pm SD daily dose of aripiprazole used in this trial was $10.26 \mathrm{mg} /$ day (SD 4.9) [66]. Authors commented that, overall, the drug was adequately tolerated in this older adult population [66].

In the unpublished literature, we identified a 12-week open-label trial of aripiprazole in the treatment of refractory bipolar depression. This study was initiated in 2004 and completed in 2009. Patients were recruited if they were aged between 18 and 75 years. No further details are currently available in the public domain, likely because the study was withdrawn (NCT00223496). Another multicenter clinical trial investigated the safety and efficacy of extended administration of oral aripiprazole in combination with a mood stabilizer for the maintenance treatment of patients with bipolar disorder experiencing a manic or mixed episode. Participants were administered open-label 12, 24, or $30 \mathrm{mg} /$ day aripiprazole for 154 days. Subjects were also coadministered a mood stabilizer. Of the 55 recruited patients, three were aged $\leq 18$ years and the rest were of adult age range (18-65 years of age, $n=52$ ). Participants' mania symptoms were monitored using the YMRS and CGI-Bipolar Version (CGI-BP) scales. The mean fall on the YMRS was -18.3 (SD 12.71), while on the CGI-BP, the mean fall was -2.4 (SD 1.76) [NCT00606320]. No statistical tests of comparison were published.

Aripiprazole has been on the market for the longest period of time compared with the rest of the reviewed atypical antipsychotics. While it offers clinically effective mood augmenting response with venlafaxine in the treatment of late-life unipolar depression [67], its safety and efficacy has not been established in OABD. With the lack of good-quality RCT data in OABD, this agent cannot be recommended for routine use.

\section{Conclusions}

As the world's population ages, it is expected that the number of patients being treated for bipolar disorder in later life will increase in both primary care and secondary care hospital settings. Given the complex needs of this group of patients, newer treatment options are sorely needed. Lithium and valproic acid remain the treatment of choice for the management of OABD based on accumulated clinical experience and confirmed by recent evidence [19]. Over the last 15 years, at least seven new atypical antipsychotics have come onto the market for the treatment of schizophrenia; however, only a few have gained marketing approval for the additional indication of treatment of bipolar disorder. Our review of these seven newer atypical antipsychotics found no RCT studies of any of these agents in any phase of 
OABD. On expanding our scope of this review, we included two post hoc studies of lurasidone, and found a reasonable efficacy profile of this agent in the acute and maintenance treatment of this illness, and hence lurasidone can be recommended for routine use. Further cost-benefit analysis of this agent remains to be investigated. Initial data from open-label studies also shows promise for the use of oral asenapine and aripiprazole as adjunctive therapy, but such findings need to be confirmed in RCTs. There are no data to support the use brexpiprazole, cariprazine, iloperidone, and paliperidone in the treatment of OABD. Future studies are sorely needed in this area.

\section{Compliance with Ethical Standards}

Funding No funding was received for the preparation of this manuscript.

Conflicts of interest Akshya Vasudev, Sumit Chaudhari, Rickinder Sethi, Rachel Fu, Rachel M. Sandieson and Brent P. Forester have no conflicts of interest to declare.

\section{References}

1. Sajatovic M, Kessing LV. Bipolar disorder in the elderly. In: Yatham LN, Maj M, editors. Bipolar disorder: clinical and neurobiological foundations. Hoboken: Wiley; 2010. p. 488-98.

2. Sajatovic M, Strejilevich SA, Gildengers AG, Dols A, Al Jurdi RK, Forester BP, et al. A report on older-age bipolar disorder from the International Society for Bipolar Disorders Task Force. Bipolar Disord. 2015;17(7):689-704.

3. Goodwin G, Haddad P, Ferrier I, Aronson J, Barnes T, Cipriani $\mathrm{A}$, et al. Evidence-based guidelines for treating bipolar disorder revised third edition: recommendations from the British Association for Psychopharmacology. J Psychopharmacol. 2016;30(6):495-553.

4. Yatham LN, Kennedy SH, Parikh SV, Schaffer A, Bond DJ, Frey BN, et al. Canadian Network for Mood and Anxiety Treatments (CANMAT) and International Society for Bipolar Disorders (ISBD) 2018 guidelines for the management of patients with bipolar disorder. Bipolar Disord. 2018;20(2):97-170.

5. Hays JC, Krishnan KRR, George LK, Blazer DG. Age of first onset of bipolar disorder: Demographic, family history, and psychosocial correlates. Depress Anxiety. 1998;7(2):76-82.

6. Goldstein BI, Carnethon MR, Matthews KA, McIntyre RS, Miller GE, Raghuveer G, et al. major depressive disorder and bipolar disorder predispose youth to accelerated atherosclerosis and early cardiovascular disease: a scientific statement from the American Heart Association. Circulation. 2015;132(10):965-86.

7. Subramaniam H, Dennis MS, Byrne EJ. The role of vascular risk factors in late onset bipolar disorder. Int J Geriatr Psychiatry. 2007;22(8):733-7.

8. Kodesh A, Goldshtein I, Gelkopf M, Goren I, Chodick G, Shalev V. Epidemiology and comorbidity of severe mental illnesses in the community: Findings from a computerized mental health registry in a large Israeli health organization. Soc Psychiatry Psychiatr Epidemiol. 2012;47(11):1775-82.

9. Shulman KI, Herrmann N. Bipolar disorder in old age. Can Fam Physician. 1999;45:1229-37.
10. Roshanaei-Moghaddam B, Katon W. Premature mortality from general medical illnesses among persons with bipolar disorder: a review. Psychiatr Serv. 2009;60(2):147-56.

11. Vasudev A, Thomas A. "Bipolar disorder" in the elderly: what's in a name? Maturitas. 2010;66:231-5.

12. Bowie MW, Slattum PW. Pharmacodynamics in older adults: a review. Am J Geriatr Pharmacother. 2007;5(3):263-303.

13. Mangoni AA, Jackson SH. Age-related changes in pharmacokinetics and pharmacodynamics: basic principles and practical applications. Br J Clin Pharmacol. 2004;57(1):6-14.

14. Harada CN, Natelson Love MC, Triebel KL. Normal cognitive aging. Clin Geriatr Med. 2013;29:737-52.

15. Sajatovic M, Chen P. Geriatric bipolar disorder. Psychiatr Clin $\mathrm{N}$ Am. 2011;34:319-33.

16. Al Jurdi RK, Marangell LB, Petersen NJ, Martinez M, Gyulai L, Sajatovic M. Prescription Patterns of psychotropic medication in the elderly compared to younger particioants who achieved a "recovered" status in the Systematic Treatment Rnhancement Program for Bipolar Disorder (STEP-BD). Am J Geriatr Psychiatry. 2008;16(11):922-33.

17. Young RC, Gyulai L, Mulsant BH, Flint A, Beyer JL, Shulman KI, et al. Pharmacotherapy of bipolar disorder in old age: review and recommendations. Am J Geriatr Psychiatry. 2004;12(4):342-57.

18. Gildengers AG, Mulsant BH, Begley AE, McShea M, Stack JA, Miller MD, et al. A pilot study of standardized treatment in geriatric bipolar disorder. Am J Geriatr Psychiatry. 2005;13(4):319-23.

19. Young RC, Mulsant BH, Sajatovic M, Gildengers AG, Gyulai L, Al Jurdi RK, et al. GERI-bd: A randomized double-blind controlled trial of lithium and divalproex in the treatment of mania in older patients with bipolar disorder. Am J Psychiatry. 2017;174(11):1086-93.

20. Chiu C-T, Wang Z, Hunsberger JG, Chuang D-M. Therapeutic potential of mood stabilizers lithium and valproic acid: beyond bipolar disorder. Pharmacol Rev. 2013;65(1):105-42.

21. Acharya S, Bussel J. Hematologic toxicity of sodium valproate. J Pediatr Hematol Oncol. 2000;22:62-5.

22. Lewis C, Deshpande A, Tesar GE, Dale R. Valproate-induced hyperammonemic encephalopathy: a brief review. Curr Med Res Opin. 2012;28(6):1039-42.

23. Anonymous. Practice guideline for the treatment of patients with bipolar disorder (revision). Am J Psychiatry. 2002;159(4):4-50.

24. Ruscin JM, Linnebur SA. Pharmacokinetics in the ElderlyGeriatrics-Merck Manuals Professional Edition. Merck Manual online. 2014. http://www.merckmanuals.com/professional/geria trics/drug-therapy-in-the-elderly/pharmacokinetics-in-the-elder ly\#v1132432.

25. Mohandas E, Rajmohan V. Lithium use in special populations. Indian J Psychiatry. 2007;49(3):211-8.

26. Mangoni AA, Jackson SHD. Age-related changes in pharmacokinetics and pharmacodynamics: basic principles and practical applications. Br J Clin Pharmacol. 2003;57(1):6-14.

27. Maeda K, Lerdrup L, Sugino H, Akazawa H, Amada N, McQuade $\mathrm{RD}$, et al. Brexpiprazole II: antipsychotic-like and procognitive effects of a novel serotonin-dopamine activity modulator. J Pharmacol Exp Ther. 2014;350(3):605-14.

28. Citrome L. Brexpiprazole for schizophrenia and as adjunct for major depressive disorder: a systematic review of the efficacy and safety profile for this newly approved antipsychotic. What is the number needed to treat, number needed to harm and likelihood to be helped or harmed. Int J Clin Pract. 2015;69:978-97.

29. Brexpiprazole for schizophrenia. Aust Prescr. 40(5):197-8.

30. Kiss B, Horvath A, Nemethy Z, Schmidt E, Laszlovszky I, Bugovics $\mathrm{G}$, et al. Cariprazine (RGH-188), a dopamine $\mathrm{D}(3)$ receptorpreferring, $\mathrm{D}(3) / \mathrm{D}(2)$ dopamine receptor antagonist-partial agonist antipsychotic candidate: in vitro and neurochemical profile. $\mathrm{J}$ Pharmacol Exp Ther. 2010;333(1):328-40. 
31. Ágai-Csongor É, Domány G, Nógrádi K, Galambos J, Vágó I, Keser GM, et al. Discovery of cariprazine (RGH-188): a novel antipsychotic acting on dopamine D 3/D 2 receptors. Bioorganic Med Chem Lett. 2012;22(10):3437-40.

32. Durgam S, Starace A, Li D, Migliore R, Ruth A, Németh G, et al. The efficacy and tolerability of cariprazine in acute mania associated with bipolar I disorder: a phase II trial. Bipolar Disord. 2015;17(1):63-75.

33. Calabrese JR, Keck PE, Starace A, Lu K, Ruth A, Laszlovszky I, et al. Efficacy and safety of low- and high-dose Cariprazine in acute and mixed mania associated with bipolar i disorder: a double-blind, placebo-controlled study. J Clin Psychiatry. 2015;76(3):284-92.

34. Mattingly G, Anderson R. Cariprazine for schizophrenia and bipolar I disorder. Curr Psychiatry. 2016;15(2):34-9.

35. Werner F-M, Coveñas R. New developments in the management of schizophrenia and bipolar disorder: potential use of cariprazine. Ther Clin Risk Manag. 2015;11:1657-61.

36. Loebel A, Cucchiaro J, Silva R, Kroger H, Hsu J, Sarma K, et al. Lurasidone monotherapy in the treatment of bipolar i depression: a randomized, double-blind, placebo-controlled study. Am J Psychiatry. 2014;171(2):160-8.

37. Ishibashi $\mathrm{T}$, Horisawa $\mathrm{T}$, Tokuda $\mathrm{K}$, Ishiyama $\mathrm{T}$, Ogasa $\mathrm{M}$, Tagashira R, et al. Pharmacological profile of lurasidone, a novel antipsychotic agent with potent 5-hydroxytryptamine 7 (5-HT7) and 5-HT1A receptor activity. J Pharmacol Exp Ther. 2010;334(1):171-81.

38. Chiu Y-Y, Ereshefsky L, Preskorn SH, Poola N, Loebel A. Lurasidone drug-drug interaction studies: a comprehensive review. Drug Metabol Drug Interact. 2014;29(3):191-202.

39. Latuda. Latuda (Lurasidone): Highlights of prescribing information.

40. Sajatovic M, Forester BP, Tsai J, Kroger H, Pikalov A, Cucchiaro $\mathrm{J}$, et al. Efficacy of lurasidone in adults aged 55 years and older with bipolar depression: post hoc analysis of 2 double-blind, placebo-controlled studies. J Clin Psychiatry. 2013;2016(2012):1-8.

41. Forester BP, Sajatovic M, Tsai J, Pikalov A, Cucchiaro J, Loebel A. Safety and effectiveness of long-term treatment with Lurasidone in older adults with bipolar depression: post-hoc analysis of a 6-month, open-label study. Am J Geriatr Psychiatry. 2018;26(2):150-9.

42. FDA, Center for Drug Evaluation and Research. Granisetron: highlights of prescribing information.

43. Crabtree BL, Montgomery J. Iloperidone for the management of adults with schizophrenia. Clin Ther. 2011;33(3):330-45.

44. Wang S-M, Han C, Lee S-J, Patkar AA, Masand PS, Pae C-U. Asenapine, blonanserin, iloperidone, lurasidone, and sertindole. Clin Neuropharmacol. 2013;36(6):223-38.

45. Richelson E. Receptor pharmacology of neuroleptics: relation to clinical effects. J Clin Psychiatry. 1999;6060(10):5-14.

46. Kalkman HO, Subramanian N, Hoyer D. Extended radioligand binding profile of iloperidone: a broad spectrum dopamine/ serotonin/norepinephrine receptor antagonist for the management of psychotic disorders. Neuropsychopharmacology. 2001;25(6):904-14.

47. Sedek G, Wolfgang C. Iloperidone is well tolerated by subjects with renal or hepatic impairment in single-dose clinical pharmacokinetic studies. In: American Psychiatric Association Annual Meeting; 19-24 May 2007: San Diego, CA.

48. Potkin SG, Litman RE, Torres R, Wolfgang CD. Efficacy of Iloperidone in the Treatment of Schizophrenia. J Clin Psychopharmacol. 2008;28(Suppl. 1):S4-11.

49. Weiden PJ, Cutler AJ, Polymeropoulos MH, Wolfgang CD. Safety profile of iloperidone. J Clin Psychopharmacol. 2008;28(Suppl. 1):S12-9.
50. Bobo WV. Asenapine, iloperidone and lurasidone: critical appraisal of the most recently approved pharmacotherapies for schizophrenia in adults. Expert Rev Clin Pharmacol. 2013;6(1):61-91.

51. Andrade C. Stahl's Essential psychopharmacology: neuroscientific basis and practical applications. Mens Sana monographs, vol. 8 . 4th ed. Barcelona, Cambridge: University Press; 2010. p. 146.

52. Pratts M, Citrome L, Grant W, Leso L, Opler LA. A singledose, randomized, double-blind, placebo-controlled trial of sublingual asenapine for acute agitation. Acta Psychiatr Scand. 2014;130(1):61-8.

53. Janssen. Product monograph: asenapine. New York: Janssen; 2003. p. $1-52$.

54. Dubovsky SL, Frobose C, Phiri P, Panagides J. Short-term tolerability, safety, and pharmacokinetic profile of asenapine in older patients with psychosis. Schizophr Res. 2010;117(2-3):263-4.

55. Corena-McLeod M. Comparative pharmacology of risperidone and paliperidone. Drugs R D. 2015;15(2):163-74.

56. Janicak PG, Winans E. Paliperidone ER: a review of the clinical trial data. Neuropsychiatr Dis Treat. 2007;3(6):869-97.

57. Knegtering R, Baselmans P, Castelein S, Bosker F, Bruggeman R, Van Den Bosch RJ. Predominant role of the 9-hydroxy metabolite of risperidone in elevating blood prolactin levels. Am J Psychiatry. 2005;162(5):1010-2.

58. Skopek M, Manoj P. Hyperprolactinaemia during treatment with paliperidone. Australas Psychiatry. 2010;18(3):261-3.

59. Vermeir M, Naessens I, Remmerie B, Mannens G, Hendrickx J, Sterkens P, et al. Absorption, metabolism, and excretion of paliperidone, a new monoaminergic antagonist, in humans. Drug Metab Dispos. 2008;36(4):769-79.

60. Berwaerts J, Lane R, Nuamah IF, Lim P, Remmerie B, Hough DW. Paliperidone extended-release as adjunctive therapy to lithium or valproate in the treatment of acute mania: a randomized, placebocontrolled study. J Affect Disord. 2011;129(1-3):252-60.

61. Berwaerts J, Melkote R, Nuamah I, Lim P. A randomized, placebo- and active-controlled study of paliperidone extendedrelease as maintenance treatment in patients with bipolar i disorder after an acute manic or mixed episode. J Affect Disord. 2012;138(3):247-58.

62. FDA Label. Aripiprazole abilify FDA-label. Interactions. 1998;50:1-25. http://pi.lilly.com/us/zyprexa-pi.pdf.

63. Shirley M, Perry CM. Aripiprazole (ABILIFY MAINTENA®): a review of its use as maintenance treatment for adult patients with schizophrenia. Drugs. 2014;74(10):1097-110.

64. H. Lundbeck A/S (Lundbeck) and Otsuka Pharmaceutical Co. L. Abilify Maintena ${ }^{\circledR}$ (aripiprazole) for extended-release injectable suspension approved by the US FDA for maintenance monotherapy treatment of bipolar I disorder. Lundbeck; 2017.

65. Leucht S, Cipriani A, Spineli L, Mavridis D, Örey D, Richter F, et al. Comparative efficacy and tolerability of 15 antipsychotic drugs in schizophrenia: a multiple-treatments meta-analysis. Lancet. 2013;382(9896):951-62.

66. Sajatovic M, Coconcea N, Ignacio RV, Blow FC, Hays RW, Cassidy KA, et al. Aripiprazole therapy in 20 older adults with bipolar disorder: a 12-week, open-label trial. J Clin Psychiatry. 2008;69(1):41-6.

67. Lenze EJ, Mulsant BH, Blumberger DM, Karp JF, Newcomer JW, Anderson SJ, et al. Efficacy, safety, and tolerability of augmentation pharmacotherapy with aripiprazole for treatment-resistant depression in late life: a randomised, double-blind, placebo-controlled trial. Lancet. 2015;386(10011):2404-12. 